DOI 10.37882/2223-2982.2021.04.03

\title{
«COVID-НЕОЛОГИЯ» РУССКОГО И АНГЛИЙСКОГО ЯЗЫКОВ, ОСНОВНЫЕ СПОСОБЫ ОБРАЗОВАНИЯ НЕОЛОГИЗМОВ В ПЕРИОД ПАНДЕМИИ COVID-19
}

\section{"COVID-NEOLOGY" OF THE RUSSIAN AND ENGLISH LANGUAGES, THE MAIN WAYS OF FORMING NEOLOGISMS DURING THE COVID-19 PANDEMIC}

\section{O. Belousova \\ K. Kokorina}

Summary: The article represents a study of neologisms in the English and Russian languages that appeared during the 2019-2020 coronavirus pandemic. The material of the research was the texts of English and Russian media and social networks. The lexical material was classified according to the main methods of word formation. According to the results of the study, the following conclusions were made: the most characteristic way of forming neologisms for the English language is blending, which refers to formal neology; also, there are examples of vocabulary formed through semantic and syntactic neology in the English discourse. In the Russian language, borrowings, blending and word composition were singled out as the main methods of neology. In addition, suffix methods and semantic neology are used as ways of forming neologisms for the Russian language.

Keywords: neology, COVID, neologisms, methods of word formation, formal neology, semantic neology, syntactic neology.
$\mathrm{H}$ аучно-технический прогресс, социальные и политические процессы, происходящие в обществе, культурные изменения, а также глобализация являются своеобразным триггером для образования различного рода неологизмов в языке, появления новых номинаций и формирования новых понятий в лингвокультуре народа.

Так, трудовые реформы советского времени запомнились всем «пятилетками» и «стахановцами», строительные проекты - ставшие уже привычными нам «сталинками» и «хрущевками». Данные лексические единицы уже прошли процесс социализации и «потеряли временную коннотацию новизны, так как употребляются носителями языка уже около двух десятков лет» [3: 6]. С начала 90-х актуальными стали такие неологизмы, как «бюджетник» и «льготник». Стремительно развивающийся технический прогресс способствует наполнению лексического состава языка технической терминологией, в современной экономике в связи с ее цифровизацией появляются различные виды «криптовалют». Факт

\author{
Белоусова Ольга Геральдовна \\ преподаватель, Военный университет Министерства \\ обороны РФ (2. Москва) \\ gero@myrambler.ru \\ Кокорина Ксения Александровна \\ Адъюнкт, Военный университет Министерства \\ обороны РФ (2. Москва) \\ small.ksen@gmail.ru
}

Аннотация: Статья представляет собой исследование неологизмов в английском и русском языках, появившихся в период пандемии коронавируса 2019-2020 гг. Материалом для исследования послужили тексты англоязычных и русскоязычных СМИ и социальных сетей. Лексический материал был классифицирован в соответствии с основными способами словообразования. По результатам исследования были сделаны следующие выводы: для английского языка наиболее характерным способом формирования неологизмов является блендинг, который относится к формальной неологии, также в английском дискурсе присутствуют примеры лексики, образованные путем смысловой и синтаксической неологии. В русском языке в качестве основных способов неологии были выделены заимствования, блендинг и словосложение. Помимо этого, в качестве способов формирования неологизмов для русского языка выступают суффиксальные способы и смысловая неология.

Ключевые слова: неология, COVID, неологизмы, способы словообразования, формальная неология, смысловая неология, синтаксическая неология.

ассимиляции неологизмов в языке также затрагивается и российским ученым Н.В. Арнольд, которая утверждает, что «неологизмы появляются и функционируют в языке по-разному, а так как лексикон языка постоянно пополняется, со временем новые слова осваиваются носителями языка и переходят из пассивного словарного запаса в активный. И как только новое слово начинает часто употребляться и становится привычным, оно ассимилируется и стилистически уже не выделяется на фоне остальной лексики» [1:56].

Можно говорить о том, что возникновение в лингвокультуре новых номинаций и неологизмов детерминировано потребностью самого общества в развитии. Кроме того, необходимо отметить тот факт, что формирование новых слов в языке может быть связано не только с техническим прогрессом и социально-политическими изменениями в стране, но и с различного рода стихийно возникающими событиями глобального масштаба.

В частности, начавшаяся в 2019 году пандемия коро- 
навируса COVID-19 также повлияла на образование новых лексических единиц в русском и английском языках, способствовала появлению добавочных коннотаций у уже имеющихся в лексиконе слов и переходу определенных специальных лексических единиц в разряд общеупотребительной лексики. Обширная деспециализация узкоспециальной лексики и профессионального арго происходит в сфере медицины. В ежедневный лексикон приходят такие медицинские лексемы и словосочетания, как «инкубационный период», «апnарат ИВЛ», «nандемия», «КТ» (компьютерная томография), контагиозность и другие. В английском языке наблюдается тот же процесс, сопровождающийся использованием специальной терминологии в разговорном дискурce: «incubation period», "artificial lung», "pandemic», «CT» (computer tomography), contagiosity. Кроме того, отдельную нишу в словообразовании, связанном с пандемией сегодняшнего времени, занимают неологизмы.

Согласно Лингвистическому энциклопедическому

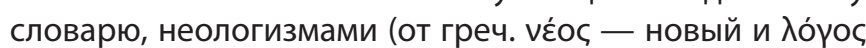
- слово) являются «слова, значения слов или сочетания слов, появившиеся в определённый период в какомлибо языке или использованные один раз («окказиональные» слова) в каком-либо тексте или акте речи» [4]. Кроме того, отмечается, что неологизмы обладают определенной относительностью и отличаются историзмом, иными словами, принадлежностью к той или иной эпохе. Таким образом, неологизмами могут также являться слова, возникающие и употребляющиеся в рамках одного поколения.

Попова Т.Г. определяет неологизмы «как новые слова и выражения, созданные для обозначения новых предметов или для выражения новых понятий». [5: 1]. К неологизмам также относятся и заимствования, отмечает ученый.

Формирование новых лексических единиц в языке обусловлено тенденциями, зафиксированными в самом языке. Как известно, язык развивается согласно определенным законам, а именно: закону развития языка и закону его сохранения, это связано с тем, что «в языке существует довольно сильная тенденция сохраняться в состоянии коммуникативной пригодности» [6: 23]. Тем не менее, для того чтобы адекватно отражать и закреплять новые предметы и явления, возникающие в окружающей действительности, «язык вообще и лексика в особенности вынуждены перестраиваться, дифференцироваться, порождать новые единицы» [3: 5]. Как утверждается ученым [3: 5], возникновение новых лексем в языке не всегда обусловлено прямой потребностью общества в новой номинации того или иного явления. Нередко неологизмы формируются в результате устранения омонимических феноменов в языке или возникновения новых ассоциаций, иными словами появление неологизмов за- частую связано с внутриязыковыми стимулами.

B период пандемии COVID-19 происходит обогащение английского и русского языков различного рода неологизмами. Лингвист Попова Т.Г. [5: 1], к способам формирования неологизмов в языке относит следующие: формальная неология, смысловая неология и синтаксическая неология. Так, для английского языка основным способом формирования неологизмов в изучаемый нами период является так называемый блендинг, который относится к лексико-синтаксическому способу словообразования формальной неологии. Отличие блендинга от словосложения состоит в том, что блендинг характеризуется усечением компонентов в составе сложного слова или их комбинациями, такое наличие квазиморфа (учесенного или «осколочного» элемента) и отличает блендинг от словосложения [7: 96]. Так, распространенными для английского языка неологизмами, образованными данным способом, стали следующие лексические единицы: covidiot, coronalusional, quarantini, maskhole, zumped, blursday.

К примеру, существительное covidiot образовано путем блендинга двух лексем covid+idiot и означает «лицо, ведущее себя безответственно и не соблюдающее меры предосторожности»: "Wish you could stand the "covidiot" in the corner and laugh at him? Denial of the basic facts of the coronavirus outbreak is not confined to conspiracy theorists but has crept into what passes for government policy. Covidiocy is now mainstream" (https://www.theguardian.com/ commentisfree/2020/sep/07/are-you-a-complete-covidiotits-what-the-government-wants-of-all-of-us-coronavirus) - Хотели бы вы поставить «ковидиота» в угол и посмеяться над ним? Отрицание основных фактов вспышки коронавируса не ограничивается теоретиками заговора, но закралось в то, что считается государственной политикой. Ковидиотизм стал массово популярным. В данном примере мы также наблюдаем изменение формы слова covidiot на более абстрактную форму covidiocy.

Следующим примером блендинга может служить неологизм coronalusional (corona+delusional), означающий индивида, страдающего одержимостью или неадекватными идеями с связи с пандемией: "Who would have thought that 'videofurbishing' would be a thing - the challenge of choosing the perfect backdrop for video calls or that we would find ourselves 'Coronalusional' - suffering from disordered thinking as a result of the Covid-19 crisis?" (https://www.step5group.com/how-can-businesses-maintain-human-connections-in-an-increasingly-virtual-world/) - Кто бы мог подумать, что «видеообстановка» станет проблемой - проблемой выбора идеального фона для видеозвонков - или что мы окажемся «короналузионистами» - страдающими расстройством мышления в результате кризиса Covid-19? В приведенном нами примере фигурирует не только исследуемый пример 
блендинга, но и пример словосложения - videofurbishing (видеообстановка).

Еще одним интересным на наш взгляд неологизмом является лексическая единица quarantini, которая означает алкогольные коктейли, употребляющиеся в период карантина во время пандемии (quarantine+martini): "In the name of making your solo cocktail session special, we've rounded up some of the tastiest (and easiest) «quarantinis» to enjoy while standing at least six feet away from other people". (https://www.townandcountrymag.com/leisure/drinks/ g31900654/quarantini-cocktail-recipes/) - Чтобы сделать вашу сольную коктейльную сессию особенной, мы собрали одни из самых вкусных (и самых простых) «карантини», которыми можно наслаждаться, стоя на расстоянии не менее шести футов от других людей.

Лексема blursday (blur+day), образованная по аналогии с днями недели в английском языке, означает феномен однообразных дней, когда индивид не в состоянии понять, какой сегодня день недели: "Is today Monday? Saturday? Every day seems like Blursday to people stuck at home". (https://news.yahoo.com/blursday-doomscrollingwords-2020-060005174.html) - Сегодня понедельник? Суббота? Людям, застрявшим дома, каждый день кажется туманным.

Еще одним выделенным нами формальным способом словообразования в английском языке является аббревиация. Так, способом аббревиации образовано само название вируса COVID - COrona VIrus Disease.

Примером смысловой неологии (приобретением нового значения) в английском языке может являться выражение zoom fatigue, означающее "усталость, истощение, вызванное чередой бесчисленных онлайн встреч и совещаний»: "Other things that might help to fight off Zoom fatigue are to block off times before and after meetings to catch your breath, and limit nonurgent calls to one or two per week". (https://www.wired.com/story/how-to-fight-zoomfatigue/) - Другие вещи, которые могут помочь бороться с усталостью om Zoom, - это выделять время до и после встреч, чтобы отдышаться, и ограничить несрочные звонки одним или двумя в неделю.

К синтаксической неологии (изменению значения слова путем перехода из одной части речи в другую) можно отнести такие примеры, как «to coronize» в значении «распространять инфекцию умышленным путем» и «to get coroned» - заразиться коронавирусом: "Don't go to Rotherham dude, it has been coroned" (https://www. urbandictionary.com/define.php?term=Coroned) - Не уезжай в Ротпердам, парень, там повсюду коронавирус.

Кроме вышеприведенных примеров, нам также представились интересными следующие неологизмы, которые были репрезентированы в английском языке: spendemic (to spend + endemic) - тратить деньги на шоппинг во время пандемии, covidicide (covid+suicide) поведение во время пандемии, граничащее с самоубийством, covidivorce (covid+divorce) - «ковидный развод» развод или расставание во время пандемии, infodemic (information+endemic) - массовое распространение одновременно достоверной и ложной информации, coronacellation (corona+cancellation) - отмена мероприятий в связи с пандемией.

В русский язык множество неологизмов приходит в качестве заимствований из английского языка. К примеру, в дискурсе стали часто фигурировать такие лексемызаимствования, как «ковидиот»: «К моим соседям снова пришла целая толпа гостей, настоящие ковидиоты» (https://www.kommersant.ru/doc/4390971), и «коронакризис»: «Коронакризис сильно отличается от финансового кризиса 2007-2009 годов: он куда более маситабный, так как одновременно затронул все страны и все индустрии, а не только ипотеку и финансовый сектор» (https://www.forbes.ru/biznes/401651-nastoyashcheenachalo-xxi-veka-kak-koronakrizis-proverit-na-prochnostrossiyu-i-mir).

Стоит также отметить, что само наименование вируса - «коронавирус» также образовано не привычным нам лексико-синтаксическим способом словообразования при помощи соединительной гласной «О», а при помощи слияния двух основ CORONA+VIRUS.

Помимо неологии заимствований русскому языку характерна смысловая неология, основанная на приобретении нового смысла или дополнительной коннотации у уже имеющегося слова. Так, новые оттенки значений приобретают такие лексемы, как «подозрительный», употребляющийся в контексте «индивида с подозрением на коронавирусную инфекцию», «контактный» В значении «имевший контакт с инфекцией». «Социальная дистанция» теперь воспринимается обществом не как дистанция по социальному статусу, а как физическая дистанция между индивидами. Кроме того, многие узкоспециальные слова ассимилируются в разговорном дискурсе, это происходит не только по отношению к медицинскому арго, но также и для сферы фриланса, откуда в разговорную речь приходят такие лексемы, как «удаленка» и «дистанционка».

Немаловажным представляется тот факт, и в самом русском языке происходят процессы формирования аутентичных неологизмов посредством формальной нелологии. К примеру, появилась лексема «карантикулы» (карантин+каникулы), образованная путем блендинга: «Как, на ваш взгляд, отразятся «карантикулы» на светотехнической отрасли в 2020 году?» (http://www.russialed-ssl.ru/kak-na-vash-vzglyad-otrazyatsya-karantikuly- 
na-svetotexnicheskoj-otrasli-v-2020-godu/). «Я неплохо подтянул свой испанский на карантикулах» (https:// www.kommersant.ru/doc/4390971). Следующим примером блендинга в русском языке можно считать лексическую единицу «ковидарность» (ковид+солидарность), которая употребляется в выражениях «проявить ковидарность» и означает «проявлять солидарность к комулибо в связи с пандемией».

Стоит отметить и то, что помимо блендинга русский язык богат и на привычные нам способы словообразования. Так, официально введенная в оборот новая лексема «самоизоляция» образована путем словосложения производящих слов с помощью соединительной гласной: «Для того, чтобы COVID-19 не распространялся дальше, предварительно по 30 апреля в Московской области введен режим обязательной самоизоляции» (https://covid.mz.mosreg.ru/quarantine/). Лексема «ковиддиссиденты» также образована словосложением, но уже производящих слов без соединительной гласной: "А именно сейчас определенная усталость отмечается. И, соответственно, вроде помнят, но усталость есть и всё больще появляется ковид-диссидентов» (https://1 prime.ru/society/20210104/832745736.html). «Люди ещё не научились жить с коронавирусом, есть рост ковид-диссидентства в Москве» (https://1 prime. ru/society/20210104/832745736.html). Последний пример также показывает изменение формы слова на более абстрактное понятие.

Суффиксальным способом по аналогии с уже ассимилировавшимися в языке «гуглить» и «скайпиться» образована такая лексема, как «зумиться» (производное от программы Zoom) - общаться онлайн посредством приложения Zoom: «Зумиться гораздо удобнее. Не тратишь время на дорогу, сразу ведется запись видеовстречи, стираются географические границы» (https://vc.ru/ finance/130800-kapitalizaciya-zoom-vpervye-prevysila50-mlrd-s-nachala-goda-ona-vyrosla-bolee-chem-vdvoe). Кроме того, в русском языке от лексем «ковид» и «коронавирус» суффиксальным способом образованы и прилагательные ковидный и коронавирусный.

Помимо этого, представились интересными следу- ющие русскоязычные неологизмы: сидидомцы - люди, выступающие за введение жестких карантинных мер, коронабесие - мракобесие во время пандемии, погулянцы - люди, выступающие за «мягкий карантин». Стал нарицательным город Коммунарка, в котором находится крупнейшая коронавирусная больница страны.

Проанализировав некоторые неологизмы и особенности их формирования, можно выделить основные с способы их образования в языке. Так, для английского языка наиболее характерными способами неологии являются те, которые относятся к формальной неологии, а именно, блендинг и аббревиация. Кроме того, в английском дискурсе широко представлены лексические единицы, образованные путем смысловой и синтаксической неологии.

В русском языке в качестве основных способов нелологии мы выделяем заимствования, в основном из английского языка, блендинг и словосложение. Помимо этого, в качестве способов формирования неологизмов выступают суффиксальные способы и смысловая неология.

Стоит отметить, что существование неологизмов в языке также, как и языковые изменения, тесно связаны с жизнью самих носителей языка, их коллективным сознанием и той эпохой, в которой они функционируют. «Жизнеспособность» того или иного слова зависит от таких факторов, как популярность и востребованность данной единицы в ежедневном дискурсе представителей той или иной лингвокультуры, ее актуальность для конкретного периода.

Мы не исключаем того факта, что многие «COVIDнеологизмы» выйдут из употребления, как только пандемия коронавируса перестанет быть ежедневной угрозой для общества. Однако, изучение современных неологизмов позволяет получить представление об основных способах словообразования в языке и выделить наиболее продуктивные из них. Перспективу исследования «COVID-лексики» мы видим в изучении не только неологизмов, но также в рассмотрении и анализе стратегий, тактик и речевых приемов, использующихся в «COVIDдискурсе» в целом.

\section{ЛИТЕРАТУРА}

1. Арнольд И.В. Стилистика современного английского языка. М.: Просвещение, 1990. - 300 с.

2. Брагина А.А. Неологизмы в русском языке: Пособие для студентов и учителей. - Москва : Просвещение, 1973. - 224 с.

3. Заботкина В.И. Новая лексика современного английского языка : [Учеб. пособие для филол. фак. ун-тов] / В. И. Заботкина. — М. : Высш. шк., 1989. — 124 с.

4. Лингвистический энциклопедический словарь / [Электронный ресурс] // Гл. ред. В.Н. Ярцева. - М. : Сов. энцикл., 1990. URL: http:// http://tapemark.narod. ru/les/331b.html (дата обращения: 18.01.2021).

5. Попова Т.Г. Научно-техническая терминология и неологизмы (на материале испанского языка) // Евразийское научное объединение. Т.2., 2015. — № 5. - С. 138-141. 
6. Серебренников Б.А. 0 материалистическом подходе к явлениям языка. — М.: Наука, 1983. — 320 c.

7. Хрущева 0.А. Блендинг в системе словообразования // Вестник оренбургского государственного университета. Оренбургский государственный университет. 2009. - № 11. - C.95-101.

8. Are you a complete covidiot? It's what the government wants of all of us / The Guardian // Электронный ресурc https://www.theguardian.com/ commentisfree/2020/sep/07/are-you-a-complete-covidiot-its-what-the-government-wants-of-all-of-us-coronavirus (дата обращения: 20.01.2021).

9. Вакцинация против Ковид-2019 / Министерство здравоохранения Московской области // Электронный ресурс https://covid.mz.mosreg.ru/quarantine (дата обращения: 20.01.2021).

10. Врач рассказал о ковид-диссидентах в Москве / Прайм // Электронный ресурс https://1prime.ru/society/20210104/832745736.html (дата 0бращения: 20.01.2021).

11. Капитализация Zoom впервые превысила $\$ 50$ млрд / Vc.ru // Электронный ресурс https://vc.ru/finance/130800-kapitalizaciya-Z0om-vpervye-prevysila-50mird-s-nachala-goda-ona-vyrosla-bolee-chem-vdvoe (дата обращения: 20.01.2021).

12. How can businesses maintain human connections in an increasingly virtual world? / Step 5 // Электронный ресурс https://www.step5group.com/how-canbusinesses-maintain-human-connections-in-an-increasingly-virtual-world (дата обращения: 23.01.2021).

13. 10 «Quarantinis» to Drink While Social Distancing / Town and Country// Электронный pecypc https://www.townandcountrymag.com/leisure/drinks/g31900654/ quarantini-cocktail-recipes (дата обращения: 23.01.2021).

14. Blursday doomscrolling words 2020 / Yahoo // Электронный ресурc https://news.yahoo.com/blursday-doomscrolling-words-2020-060005174.html (дата 0бращения: 23.01.2021).

15. How to Beat Zoom Fatigue / Wired.com // Электронный ресурс https://www.wired.com/story/how-to-fight-zoom-fatigue (дата 0бращения: 23.01.2021).

16. Coroned / Urban Dictionary // Электронный ресурс https://www.urbandictionary.com/define.php?term=Coroned (дата 0бращения: 25.01.2021).

17. Инфодемия, карантикулы и ковидиворс / Комерсант // Электронный ресурс https://www.kommersant.ru/doc/4390971 (дата 0бращения: 25.01.2021).

18. Настоящее начало XXI века: как коронакризис проверит на прочность Россию и мир / Forbes // Электронный pecypc https://www.forbes.ru/biznes/401651nastoyashchee-nachalo-xxi-veka-kak-koronakrizis-proverit-na-prochnost-rossiyu-i-mir (дата обращения: 25.01.2021).

19. Как на ваш взгляд отразятся карантикулы на светотехнической отрасли в 2020 году / Russia-led-ssl.ru/ // Электронный pecypc http://www.russia-led-ssl. ru/kak-na-vash-vzglyad-otrazyatsya-karantikuly-na-svetotexnicheskoj-otrasli-v-2020-godu (дата обращения: 25.01.2021).

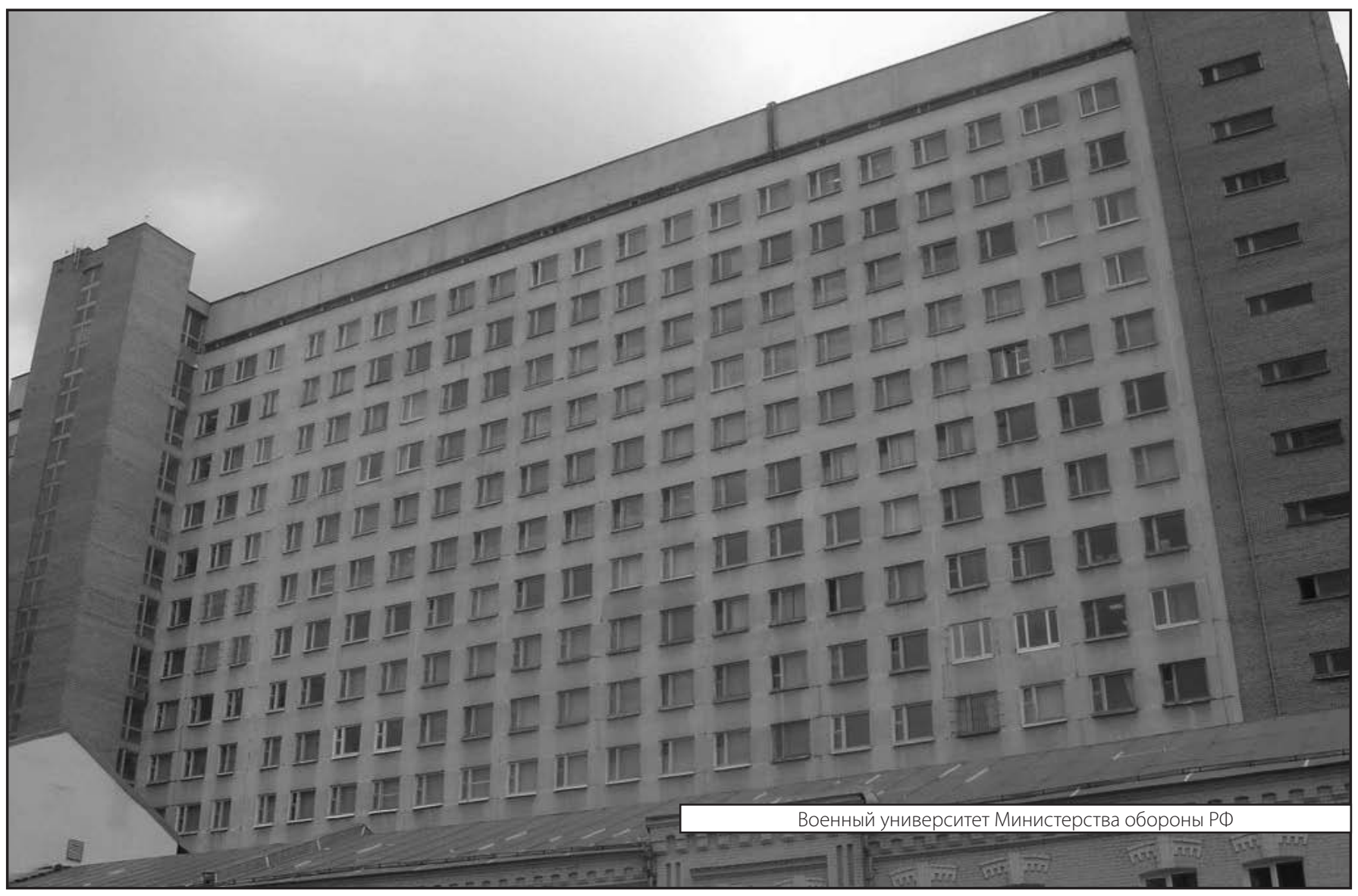

